\title{
Injectable contraceptives: A worldwide perspective
}

Approximately 25 million women around the world are currently using long-acting injectable contraceptives, mostly in developing countries, and the number of users is increasing. It is generally believed that the popularity of such methods would considerably increase if they were further improved. Table 1 describes the current status of injectable contraceptives which are either available in the market or under development.

Injectable hormonal contraceptives, when properly used, are amongst the most effective methods of contraceptive available today. They combine almost complete effectiveness with reliable reversibility. Most clinical trials report less than 1 pregnancy per 100 women in the first year. Thus they should be included among the family planning methods available at any clinic or other health facility offering an integrated family planning service. It is estimated that over 40 million women worldwide have used this method and approximately 25 million are using it currently. Injectable hormonal contraceptives are licensed for contraceptive use in more than 106 countries.

Two injectable contraceptives are widely available: depot medroxyprogesterone acetate (DMPA) and norethisterone enanthate (NET-EN). DMPA is usually given in a 3-month dose of $150 \mathrm{mg}$. NET-EN is recommended for administration using $200 \mathrm{mg}$ at either 8-weekly intervals or every 8 weeks for the first 6 months and then every 12 weeks. Both DMPA and NET-EN are highly effective, with annual pregnancy rates of less than 1 per 100 users. They have few side effects apart from menstrual disturbances. Some women using DMPA gain weight; usually from 1 to $5 \mathrm{~kg}$. Most women do not become fertile for 4 or 5 months after discontinuing use, but there is no evidence that fertility is permanently impaired. Injectables have non-contraceptive benefits. Some lactating women taking DMPA may have an increased supply of breast milk. Injectables, in common with oral contraceptives, reduce the risk of pelvic inflammatory disease (PID).

Concern about injectables focused on studies in beagle dogs, which developed benign and malignant breast tumors, and studies in monkeys, which developed endometrial cancer while receiving high doses of these hormones. However, these animal studies are not relevant to humans. In particular, testing high doses of hormones in beagle dogs, which have a high naturally occurring incidence of breast tumors, has been challenged. Studies of humans using injectables have shown no increased risk of cancer. A large, multicenter, case-control study conducted by the Special Programme of Research, Development and Research Training in Human Reproduction of the World Health Organization (WHO) provided clearer answers to the cancer question. The results showed no added risk of breast or cervical cancer with DMPA use. In addition, a number of methodologically sound studies of combined oral contraceptives (COCs) suggested that, in humans, progestins protect against endometrial and ovarian cancer and have no effect on breast cancer risk. In fact, progestins, including DMPA, are used to treat endometrial cancer. After examining the cancer issue, the WHO Toxicology Review Panel and the International Medical Advisory Panel of the International Planned Parenthood Federation, as well as many other medical bodies, have endorsed the use of DMPA. ${ }^{1,2}$

Only about $10 \%$ of DMPA users have normal cycles in the first year of use. DMPA users can expect to have irregular bleeding in the first 6 months and then infrequent bleeding or amenorrhoea in the next 6 months and beyond. By comparison, in a WHO trial of six COCs, $59 \%$ to $87 \%$ of women had normal bleeding patterns after 1 year. NETEN has somewhat less effect on bleeding patterns than DMPA. In a comparative trial, bleeding episodes in the first 6 months were significantly shorter among NET-EN users than among DMPA users. Bleeding patterns after 6 months were similar, however. Amenorrhoea lasting more than 90 days was significantly less common among NET-EN users.

With a view to improving the bleeding patterns of the injectable contraceptives, oestrogen was added to DMPA, and other progestins. In 1988, the WHO reported on a phase III multicentre comparative study of Cyclofem and Mesigyna. A total of 2320 women were recruited into a 17 centre, random allocation clinical trial. Over 1 year of follow-up, 10969 woman-months of use were collected for Cyclofem and 10608 woman-months for Mesigyna. Two pregnancies occurred, both with Mesigyna, one in the second and one in the third injection interval, giving a life table rate of 0.18 per 100 woman-years. Heavy, prolonged, irregular bleeding or a combination of these accounted for a discontinuation rate of $6.3 \%$ with Cyclofem and $7.5 \%$ with Mesigyna, while discontinuation rates for amenorrhoea were low at $2.1 \%$ (Cyclofem) and $1.6 \%$ (Mesigyna). The overall total discontinuation rates were $35.5 \%$ for Cyclofem

Table 1 Status of injectable contraceptives (2001)

\begin{tabular}{|c|c|c|c|}
\hline Type & Duration & Existing systems & Status \\
\hline Injectable & Monthly & $\begin{array}{l}\text { 1. } 25 \mathrm{mg} \text { DMPA + } 5 \mathrm{mg} \mathrm{OC} \text { (Cyclofem) } \\
\text { 2. } 50 \mathrm{mg} \text { NET-EN }+5 \mathrm{mg} \mathrm{OV} \text { (Mesigyna) } \\
\text { 3. } 250 \mathrm{mg} \mathrm{HPC}+5 \mathrm{mg} \mathrm{OV} \\
\text { 4. } 150 \mathrm{mg} \text { DHPA + } 10 \mathrm{mg} \mathrm{OE}\end{array}$ & $\begin{array}{l}\text { Market } \\
\text { Phase IV } \\
\text { Market (China) } \\
\text { Market (Mexico) }\end{array}$ \\
\hline Injectable & 2-3-Monthly & $\begin{array}{l}\text { 1. } 200 \mathrm{mg} \text { NET-EN } \\
\text { 2. } 150 \mathrm{mg} \text { DMPA } \\
\text { 3. } 100 \mathrm{mg} \text { NET microcapsules }\end{array}$ & $\begin{array}{l}\text { Market } \\
\text { Market } \\
\text { Phase II }\end{array}$ \\
\hline Injectable & 6-Monthly & $\begin{array}{l}\text { 1. } 450 \mathrm{mg} \text { DMPA } \\
\text { 2. } 200 \mathrm{mg} \text { NET microcapsules }\end{array}$ & $\begin{array}{l}\text { Market } \\
\text { Phase I }\end{array}$ \\
\hline
\end{tabular}

Abbreviations: DMPA, depot medroxyprogesterone acetate; OC, oestradiol cypionate; NET-EN, norethisterone enanthate; OV, oestradiol valerate; HPC, hydroxyprogesterone caproate; OE, oestradiol enanthate; DHPA, dihydroxyprogesterone acetophenide. 
and $36.8 \%$ for Mesigyna at 1 year. Discontinuations for other medical reasons were low for both preparations. ${ }^{2-4}$

In many developing countries women prefer injectables to other methods because they are considered a practical and potent medicine. For example, in Indonesia, by December 2000, approximately 10 million women $(38.3 \%$ of total users) were currently using injectables as their method of choice.

Statements on funding and competing interests

Funding. None declared.

Competing interests. None declared.
Biran Affandi, MD, $\mathrm{PhD}$

Professor of Obstetrics and Gynaecology, University of Indonesia, Klinik Raden Saleh 49, Jakarta 10330, Indonesia. Tel: (62) 21 3143684. Fax: (62) 213910135. Email:biran@indo.net.id

World Health Organization (WHO). Facts about injectable contraceptives. Bull World Healt Organ 1982; 60: 199-210.

World Health Organization (WHO). Facts about once-a-month injectable contraceptives memorandum from a WHO meeting. Bull World Health Organ 1993; 70: 677-689. uesc $\mathrm{C}$, Hall PE. Once-a-month combined injectable contraceptives. Obstet Gynecol 1994; 14: S1-S34.

nal contraception In: Kempers J, Cohen J, Haney AF, Younger JB (e) Ferility and reproductive medicine. New York, NY. Elsevier, 1998: 295-308.

\section{Progress for The Journal of Family Planning and Reproductive Health Care}

\section{Electronic journal}

The on-line Journal is here and can be accessed at www.ffprhc.org.uk. There are two Journal items on the Faculty website home page. The icon of the front of the Journal will take you into the journal contents. This will mean full text for everyone for the next 6 months. From July 2002 access to full text will be for Faculty members and subscribers only. Non-members and non-subscribers will be able to access abstracts only and full text on a 'payper-view' basis. Clicking on the word 'Journal' will take you into information about the Journal including 'Notes for Contributors', 'Peer Review Policy', 'Management of Competing Interests', and subscription details.

\section{Creation of new Editorial Board}

We have established a new Editorial Board and welcome Anne Calder, Rebecca Hobbs and Nick Mannassiev as Associate Editors. Susan Brechin has joined the Board as a Trainee Editor with special responsibility to commission, research and edit items for the Bulletin Board and Journal Club sections (see later). Julie Simpson and Jill Mollison are job-sharing the role of Statistical Advisor and will be assisting in the peer review process from the methodology and statistical perspective.

\section{Restructuring the Editorial Advisory Board}

The Editorial Advisory Board has been restructured with advisors allocated responsibility for specific elements of advice needed to guide the Journal's development. There are currently vacancies for a Service Advisor, Academic Advisor, Nurse Advisor (Co-opted) and International Advisors (Corresponding) (see advert on page 51).

\section{Bulletin Board and Journal Club}

The 'News' has evolved into the 'Bulletin Board'. Running a 'News' section in a quarterly journal was an impossible task because 'News' needs to be new! The 'From the Journals' section has evolved into 'Journal Club'. Potential items for either section are always welcome and should be sent (preferably by e-mail) to the Journal Editorial Office journal@ffprhc.org.uk marked for the attention of Susan Brechin.

\section{Notes for Contributors}

The Notes for Contributors will be revised annually and appear in print form every January at the start of a new volume. They will also be accessible on the website at www.ffprhc.org.uk throughout the year.

Fran Reader, FRGOG, MFFP

Editor-in-Chief, The Journal of Family Planning and Reproductive Health Care

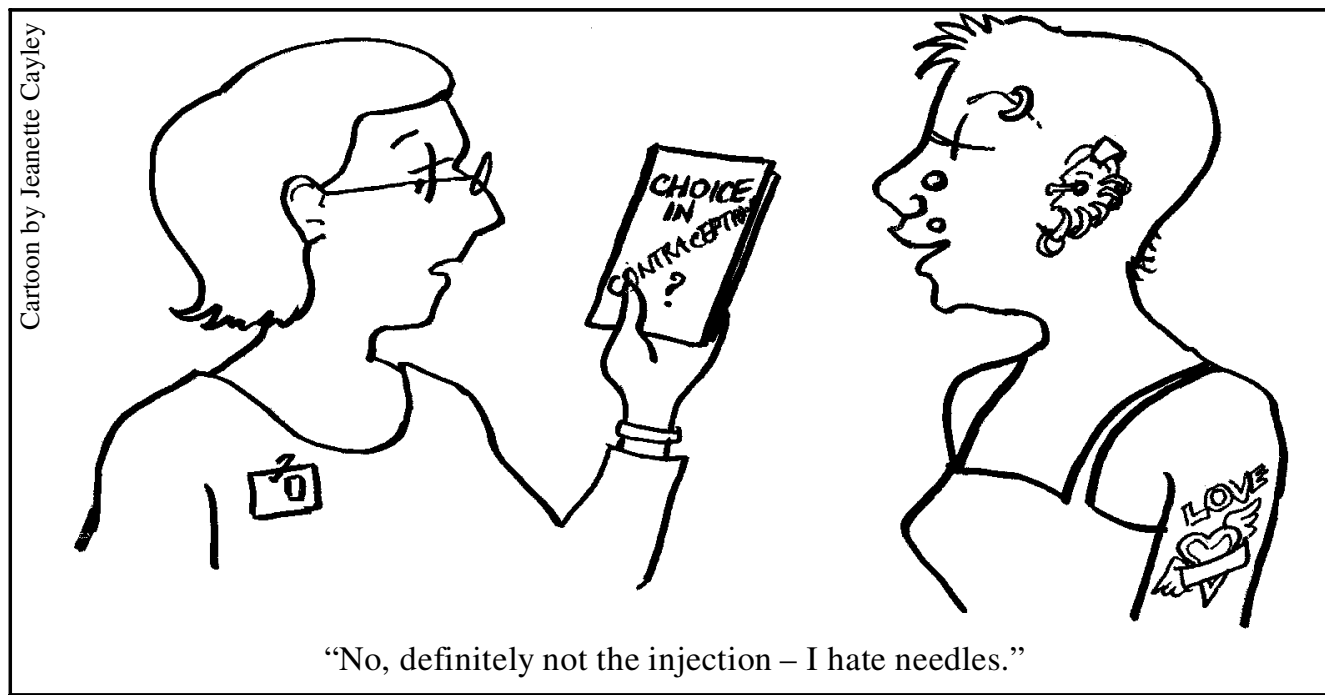

